\title{
DESAFÍOS DE LA EDUCACIÓN SUPERIOR EN AMÉRICA LATINA
}

\section{REFLEXIONES DESDE LA IGLESIA CATÓLICA}

Mons. Dr. Julio Terán Dutari

Responsable de la Sección Educación del CELAM

Quienes han dedicado mucho de su trayectoria de vida a la Universidad, saben muy bien que la educación superior en América Latina y el Caribe afronta hoy especiales desafíos: ante todo, el desafío de reposicionarse en este continente mayoritariamente joven, y donde cada día más jóvenes quieren ingresar a un ámbito que antes les habría parecido vedado.

La Iglesia Católica sigue con especial atención el desarrollo de esta problemática, no sólo por su preocupación pastoral, sino también por su visión filosófica de la juventud, de la educación y del quehacer educativo en nuestra vida pública. Desde que se reunió la famosa II Conferencia General del Episcopado en Medellín (1968) hubo declaraciones y compromisos expresos sobre la Universidad y las instituciones de educación superior. Igual interés, acrecentado por nuevos retos, se ha hecho presente en las Conferencias de Puebla (1979) y Santo Domingo (1992). Desde hace diez años se viene institucionalizando la reflexión sobre este tema en el Consejo Episcopal Latinoamericano CELAM, cuando se dieron cita en El Salvador rectores provenientes de algunas Universidades Católicas y de 
inspiración cristiana de México, Centro América y el Caribe. Entonces se reunían no únicamente para discutir problemas prácticos, sino ante todo para aquilatar la concepción misma de la educación superior; así lo han hecho, al extenderse también ese grupo de trabajo a los Países Bolivarianos, a Brasil, al Cono Sur, y finalmente a todo el ámbito latinoamericano y del Caribe, en una apertura continental que con esfuerzos similares se reproduce dentro de otras organizaciones interuniversitarias.

Una muy importante labor reflexiva se lleva adelante también en la Federación Internacional de Universidades Católicas FIUC, hoy particularmente atenta a su sección latinoamericana. Por otra parte, y como la expresión más universal de esta reflexión filosófica cristiana, hay que anotar los estudios de la Congregación Vaticana para la Educación Católica, el órgano por el cual el Sumo Pontífice ejerce para los católicos, en los campos de la escuela y la academia, su ministerio de enseñar y promover la verdad.

Estos impulsos académicos y eclesiales han tenido recientemente una confluencia fecunda en un nuevo encuentro de representantes de esos altos organismos con Rectores de universidades católicas latinoamericanas, bajo la anfitrionía de la Universidad Católica Argentina, encuentro celebrado en septiembre de 2006, en Buenos Aires, y en una hora providencial para la Iglesia en América Latina: el camino hacia la quinta conferencia de su episcopado.

Allí quedó de manifiesto, ante todo, lo que es primordial: la fundamental preocupación de la Iglesia en este continente por la juventud universitaria. Es que, a diferencia de lo que ha sido la tradición de venerables instituciones científicas de nivel superior en otras latitudes, aquí en nuestras tierras el tema universitario, con todas sus ricas complejidades, se ha venido polarizando hacia el 
estamento estudiantil. La misma juventud de nuestros países parece encontrar en la Universidad uno de sus iconos predilectos. Se va creando una cierta 'cultura universitaria', un estilo de vida en juventud, con interés por estudiar, pero también por disfrutar de la convivencia abierta e igualitaria, en un nuevo compromiso por el mundo y en esa inquietud universal del espíritu humano que corresponde al nombre originario de la 'universitas'. También el profesorado y toda la planta universitaria quedan poderosamente influidos por este ambiente de los jóvenes. A ese sector poblacional mayoritario, de juventud inquieta, a veces enigmática, frágil y con frecuencia desorientada y amenazada dentro del festín de la globalización y del libre mercado, a ellos y ellas se dirigía el interés de aquel encuentro, que identificaba "el mundo universitario latinoamericano" entendiéndolo como "espacio de cooperación viva en misión".

Cooperación viva en misión: este programa estaba allí referido a las universidades católicas, llamadas a cooperar y ayudarse mutuamente en su responsabilidad frente a la juventud que se les confía; pero con ellas y más allá de ellas el programa ratificaba la convicción con la que toda la Iglesia acepta el desafío del mundo joven: el mundo universitario latinoamericano es importante para la Iglesia Católica, no primordialmente porque pueda ingresar o no en el campus de sus propias instituciones, sino porque tiene necesidad de que se lo entienda y se lo acepte dentro de una auténtica visión filosófica, que -por lo demás- guarda innegables rasgos de enganche con la actual propuesta educativa católica.

En efecto, todas las actividades de la Iglesia, puestas en contacto con esta juventud universitaria nuestra, se revelan conducentes para la tarea educativa. Y se hace más urgente esa tarea, en el momento en que la misma educación se ve afectada por tantas corrientes forá- 
neas que abusan del término, al hablar de una 'educación' que es mera instrucción intelectualista, sin referencia a la responsabilidad social del saber. Se quita así, implícita y aun explícitamente, de la actividad universitaria el factor educativo, convirtiéndola en oferta de mercado para capacitar fuerzas productivas; o, lo que es peor, convirtiendo al ambiente universitario en espacio de irrestrictas libertades, sin deberes ni compromisos con la vida, la familia, el futuro, el inmenso mundo de los pobres y excluidos.

Un eje insoslayable de la preocupación de la Iglesia frente al mundo joven y universitario se señala, pues, en ese lema: "ser espacio de cooperación viva". La Iglesia sigue teniendo en nuestros países capacidad de convocatoria. Pero no siempre para todos sus proyectos. Es un hecho que en sus muchas y, por lo general, bien cualificadas instituciones universitarias de inspiración cristiana, cuenta con un precioso instrumento para dirigirse a los jóvenes, cumpliendo su misión de hacer crecer el Reino de Dios en nuestros pueblos a través de la educación en su máximo nivel. Y así se cumple también el mejor servicio a nuestra juventud.

Sin embargo, al soñar con una mayor y mejor colaboración entre sus propias instituciones, la Iglesia insiste también en que hay necesidad urgente de colaborar entre todas las instituciones del ámbito de la educación superior, sean estatales o privadas, confesionales o laicas, tratando de dialogar incluso con aquellas que se rinden a la pura comercialización del saber (o mejor dicho: de los títulos académicos que pretenden justificarse con el saber).

Y todo esto viene enmarcado en el tema de la Quinta Conferencia del Episcopado Latinoamericano, preparada por el CELAM para mayo de 2007, en Aparecida, Brasil: "Discípulos y Misioneros de Cristo". El discipulado es la manera de educación que promovió Jesús y que la Iglesia lleva adelante. En ella se contiene una filosofía de 
la juventud y de su desarrollo, a través de la búsqueda de la verdad y del bien, que puede ser compartida con inmenso provecho aun por los no creyentes.

Del discipulado surge la misión. Y también de la educación debe surgir el envío hacia un servicio al mundo y a la sociedad. Porque finalmente, ¿para qué es la educación? A esta pregunta responde también el tema de la Quinta Conferencia: "para que nuestros pueblos tengan vida". La Iglesia entiende que no puede encerrarse sobre sí misma, dirigiendo su pastoral al puro robustecimiento de grupos institucionalmente suyos. Ahora menos que nunca lo pretende. Pero entiende también que en Cristo se encuentra esa vida sobreabundante que nuestros pueblos buscan. Los rasgos fundamentales de esa vida en Cristo son otros tantos rasgos de la visión filosófica del futuro que anhelamos para nuestros pueblos. En efecto, la Carta Magna de las universidades, dada por el Papa Juan Pablo II, señala que el encuentro fecundo entre fe y cultura tiene que dar respuestas operativas a las grandes cuestiones de la humanidad; y eso significa para nosotros: responder a las cuestiones de nuestro continente joven y esperanzado, dividido sin embargo por brechas crecientes de opresión y de muerte. El mundo que debe humanizarse en Cristo es para nosotros en primer lugar el mundo joven latinoamericano, tan influido - para bien o no - por los centros del poder global, también en cuanto a estilos universitarios.

Los estados latinoamericanos y todas las comunidades de nuestros pueblos deben reconocer la importancia de la educación superior en la transformación de la sociedad, no sólo como voz crítica y profética sobre el mundo, sino además como forjadora de quienes harán su futuro. Para ello es necesario mejorar las relaciones entre la comunidad universitaria, las instancias oficiales de la educación y los agentes culturales. La Iglesia, con sus ins- 
tituciones de educación superior, puede entrar en una relación mediadora entre los agentes de cultura, que tienda a establecer un nuevo "pacto cultural".

Así pues, en paralelo con algunas reflexiones surgidas de aquel encuentro universitario y eclesial de Buenos Aires 2006, se pueden enunciar aquí algunos rasgos de la nueva problemática de la educación superior que va surgiendo en América Latina ${ }^{1}$ y de los objetivos que deberían dirigir acciones concretas, destinadas a enfrentar los nuevos desafíos.

En un clima de relativismo cultural, donde todo es verdad y, por lo tanto, nada es verdad, la educación superior tiene hoy el desafío de redefinirse como el lugar donde sea operante una trilogía fundamental: libertad, verdad y diálogo. Allí podrá tener sentido y vigencia transformadora el concepto de "consenso". En esta empresa la fe es una verdadera aliada de la razón y abre grandes perspectivas ante aquellas preguntas sobre las que se construye la cultura: las interacciones entre grupos sociales y generacionales, los vínculos con el pasado y el futuro, el sentido de la vida y de la muerte, no sólo para los individuos sino también para las sociedades. Es necesario un verdadero encuentro de fe y razón, que debe mantenerse interdisciplinariamente, con respeto y apertura, entre los distintos campos epistemológicos. Concretamente se podrían vislumbrar los siguientes objetivos:

1. Promover una pasión por la verdad: confrontar el constante relativismo que impregna nuestra sociedad, dirigiendo el trabajo académico hacia la realidad como es y como debe ser.

2. Favorecer la sintesis del saber: superar la desintegración del saber contemporáneo, caracterizado por un alto nivel de información fragmentada que sólo lleva a resultados desarticulados e inconexos. 
3. Fomentar un nuevo humanismo integral: dejar atrás el concepto de la educación superior como mero instrumento de preparación de una carrera, considerado como una "inversión"; combatir la comercialización de la educación con la exigencia de una antropología sólida, que integra en los planes de estudio la verdad sobre el hombre.

Desde el tiempo de la IV Conferencia del Episcopado Latinoamericano (Santo Domingo, 1992), el mundo atraviesa un período de nueva actividad intelectual que provoca un cambio tecnológico y de relaciones interpersonales -virtuales- sin precedentes. La sociedad del conocimiento globalizada, aunque no es una realidad perfecta, ha exigido ya grandes cambios. Junto con el nuevo orden internacional, se está preparando una nueva sociedad, marcada por los criterios del mercado único; y en consecuencia se intenta convertir a las universidades en el lugar de capacitación de fuerzas destinadas al buen funcionamiento de un inmenso aparato de producción. ${ }^{2}$ Sin embargo, criticamos el sistema sin tomar plena conciencia de que ha sido formado y sostenido mayoritariamente por universitarios. ¿ $\mathrm{H}$ Ha faltado en nosotros y en ellos conciencia verdaderamente crítica y creativa, responsabilidad auténticamente universitaria? Lo cierto es que hoy día se da la impresión de que las instituciones de educación superior actúan repitiendo lo que va señalando el mercado global. El comportamiento de las universidades suele ser de réplica en lugar de ser proactivo e inventor de modelos confiables.

La educación superior se ha transformado en un campo cada vez más central de la política pública y también de la geopolítica global. Se está dando un tránsito de la educación, como un servicio de importancia social vinculado a las fronteras e instituciones del respectivo 
país, hacia una educación como servicio mercantil que supera las fronteras nacionales, gracias a las nuevas tecnologías de transmisión y gestión, vinculado al mercado global. La enseñanza "en línea" cuenta con instituciones especializadas que multiplican cursos virtuales de una expansión creciente y preocupante. La concepción sobre el fin y naturaleza de la educación se va reorientando a la luz de esta nueva lógica. Frente a ello, la Universidad debe reafirmar su compromiso con la verdad del ser humano en su esencia dialógica y social, en su desarrollo histórico, en su ineludible vocación trascendente; y enfrentar el especial desafío de superar las reglas del mercado, asumiendo los innegables avances científicos y tecnológicos dentro de una integración del saber que promueva un humanismo integral, de acuerdo con su irrenunciable misión. Y en este compromiso quieren estar presentes las instituciones de Iglesia, en tanto que universidades y también en tanto que católicas o de inspiración cristiana. ${ }^{3}$

\section{Notas}

1 La Educación superior en América Latina cubre una matrícula aproximada de 15,5 millones de estudiantes. Un 52 \% correspondería a la educación de gestión pública y un $48 \%$ a la de gestión privada. La demanda de matrícula crece a un ritmo superior al de la población, lo que provoca una fuerte tensión entre las necesidades y las oportunidades educativas. En la región existen 280 universidades de orientación religiosa, siendo el 77\% católicas, es decir, 216. Todos los credos avanzan en la nueva etapa de transnacionalidad de la educación tratando de captar a la juventud. Recordemos que la región representa el $42 \%$ de la matrícula católica mundial, con una realidad de 216 instituciones y una matrícula aproximada a un millón quinientos mil alumnos. Dentro de las nuevas realidades universitarias confesionales, se pueda clasificar como Universidades "nuevas" a aquellas que se formaron en los últimos veinte años en América Latina. Son reflejo de los "nuevos signos de los tiempos" del mundo globalizado. No re- 
cibieron la categoría de pontificias. Muchas de ellas tienen una fisonomía que las asemeja al modelo de las business universities: ofrecen carreras más cortas y de rápida salida en el mercado laboral flexible del nuevo orden poscapitalista. Tiene estructuras edilicias modernas y buenos contactos académicos. Están en consonancia con los últimos años de la historia reciente latinoamericana, caracterizados por gobiernos democráticos y más sensibles al intercambio con América del Norte que con Europa Occidental. (Informe del encuentro de Buenos Aires 2006).

2 Sin duda estamos ante una realidad diferente en el área de la educación superior. A la gestión estatal y privada nacional se añade la internacional. La educación virtual tiene una tasa de crecimiento mayor a la presencial. Se multiplican las universidades. Se incrementa la competencia y las agencias de regulaciones, evaluaciones y acreditaciones. Las universidades extranjeras compiten con las universidades locales incidiendo sobre las características del proceso de enseñaza-aprendizaje y sobre los mismos estudiantes con un criterio dominante de estandarización comercial que sin duda produce alteraciones culturales. Un estudio realizado por la Federación Internacional de Universidades Católicas, en Entebbe (Uganda -África), en julio del 2003, comprueba que aproximadamente el $85 \%$ de las páginas Web están en inglés, pero sólo el $10 \%$ de la población mundial lo habla. La transformación del mundo se presenta como asunto de todos, pero el dominio de esta transformación sigue siendo un campo reservado a una minoría. (Informe del encuentro de Buenos Aires 2006).

3 Para estas instituciones se vuelve más urgente el trabajo ya señalado desde Pablo VI: la evangelización de la cultura, la inculturación del evangelio y un verdadero humanismo. Pero ahora se hace necesaria una revisión de los acercamientos filosóficos y teológicos, ya que los sujetos y sus situaciones culturales han cambiado. Por ello, hace falta una actualización de currículos en una cultura cambiante, pero con entera fidelidad al mismo mensaje evangélico. Hay que proponer la fe sin miedo, pero no imponerla. En este sentido, se debe cuidar que los contenidos y métodos del proyecto educativo tengan presente a Jesucristo Maestro, vinculando antropología y cristología, ya que de por medio está, como problema existencial, el sentido de la vida y la cuestión del hombre (Informe del encuentro de Buenos Aires 2006). 